\title{
O PNE E AS POLÍTICAS EDUCACIONAIS NO DEBATE ATUAL*
}

Lourival Júnior Alves de Holanda**

\section{RESUMO}

O objetivo deste artigo é compreender o Plano Nacional de Educação (PNE), tendo como ponto de partida para análise o processo de aprovação da Lei n. 10.172/1996 pelo Congresso Nacional, dentro do contexto das mudanças operadas na política educacional nos últimos anos, com a finalidade de adequála às propostas de reforma e de ajustes do Estado brasileiro, em conformidade com as orientações dos organismos de cooperação internacional. Busca-se evidenciar a importância do PNE no atual debate educacional.

Palavras-chave: PNE; política educacional; Estado; ajustes estruturais.

Em janeiro de 2001, foi sancionado o Plano Nacional de Educação (PNE) - Lei n. 10.172/2001 -, composto de um diagnóstico da realidade educacional brasileira e das diretrizes e das metas a serem executadas por todos os entes federados nos próximos dez anos. Traz também a obrigatoriedade de Estados, Distrito Federal e municípios elaborarem seus respectivos planos decenais. A promulgação do PNE fecha um ciclo de profundas mudanças que caracteriza a "nova" política educacional para o país.

Essas mudanças, iniciadas no final da década de 1980, aprofundaram-se no período compreendido entre 1995 e 2000, durante o primeiro e o segundo governo do presidente Fernando Henrique Cardoso, desencadeando uma série de reformas nos marcos e mecanismos legais do campo educacional. Tais mudanças visam implementar os acordos e

\footnotetext{
* Artigo recebido em 11/06/2005 e aprovado em 15/07/2005.

** Professor da Secretaria de Estado da Educação de Sergipe. [e-mail: ljuniorh@hotmail.com]
} 
as orientações dos organismos internacionais, sobretudo o Banco Mundial, que implicaram em uma nova organização sistêmica e repercutiu no próprio pacto federativo, caracterizando-se pela descentralização da execução das políticas sociais e de parte dos recursos financeiros, bem como pela desresponsabilização ou descompromisso da União na oferta dessas políticas, prevalecendo a centralização do processo decisório e de avaliação.

Tivemos nesse período, para exemplificar, a extinção do Conselho Federal de Educação e a criação do Conselho Nacional de Educação (Lei n. 9.131/1995), a Emenda Constitucional 14, que cria o Fundo de Manutenção e Desenvolvimento do Ensino Fundamental e de Valorização do Magistério (Fundef), regulamentado pela Lei n. 9.424/1996, e a aprovação de uma nova Lei de Diretrizes e Bases da Educação Nacional (LDB), Lei n. 9.394/1996. No cenário internacional, no tocante à educação, realizou-se a Conferência Mundial de Educação para Todos, em Jomtien, na Tailândia, e as demais conferências posteriores de avaliação de Jomtien promovidas pela Organização das Nações Unidas (ONU) ou por grupos de países, como também a implantação das propostas de ajustes neoliberais, fatores que vão apontar para a reorganização e a redefinição das políticas educacionais.

No Brasil, a necessidade de elaboração de um Plano Nacional de Educação, como marco legal que contribua para o planejamento da educação nacional, no sentido de orientar as ações do Poder Público e direcionar a política educacional, surge pela primeira vez nos anos 1930, mais especificamente em 1932, quando do lançamento do Manifesto dos Pioneiros da Educação Nova, "o qual afirmava a necessidade central de se desenvolver 'um plano unitário e de bases científicas' para a educação brasileira" (MANIFESTO apud Silva, 2002, p. 45).

O 'Manifesto' após diagnosticar o estado da educação pública no Brasil [...], irá enunciar as diretrizes fundamentais e culminar com a formulação de um 'Plano de reconstrução educacional'.

Pela leitura global do 'Manifesto', pode-se perceber que a idéia de plano de educação se aproxima, aí, da idéia de sistema educacional, isto é, a organização lógica, coerente e eficaz do conjunto das atividades educativas levadas a efeito numa sociedade determinada ou, mais especificamente, num determinado país.

Trata-se, no caso em questão, do conceito de plano entendido como instrumento de introdução da racionalidade científica no campo da 
educação em consonância com o ideário escolanovista. (SAVIANI, 1998, p. 75)

Por influência dos "pioneiros", a Constituição Federal (CF) de 1934 estabeleceu no seu artigo 150, alínea a, que compete à União "fixar o plano nacional de educação, compreensivo do ensino de todos os graus e ramos, comuns e especializados; e coordenar e fiscalizar a sua execução, em todo o território do país". A CF de 1934 também previu a criação de um Conselho Nacional de Educação - artigo 152 -, cuja principal tarefa era a de elaborar e fiscalizar a aplicação do plano nacional de educação. Desde então, com exceção da Constituição Federal do Estado Novo, outorgada em 1937, em todas as demais constou essa necessidade e incumbência da União. Porém, o nosso primeiro plano nacional de educação foi elaborado pelo Conselho Federal de Educação somente em 1962, como cumprimento do estabelecido na Lei de Diretrizes e Bases, de 1961. Na primeira parte do referido plano, o documento procurou

traçar as metas para um Plano Nacional de Educação e, numa segunda parte, estabelecer as normas para aplicação dos recursos correspondentes aos Fundos do Ensino Primário, do Ensino Médio e do Ensino Superior. (SAVIANI, 1998, p. 78)

O segundo Plano Nacional de Educação foi elaborado em conformidade com a Constituição Federal de 1988, que determina, no artigo 214, que deverá ser estabelecido o "plano nacional de educação, com duração plurianual, visando à articulação e ao desenvolvimento do ensino em diversos níveis e à integração das ações do Poder Público". De acordo com a CF de 1988, essa articulação e integração devem conduzir: (i) à erradicação do analfabetismo; (ii) à universalização do atendimento escolar; (iii) à melhoria da qualidade do ensino; (iv) à formação para o trabalho; e (v) à promoção humana, científica e tecnológica do país (BRASIL, CF, 1988).

A LDB de 1996 reafirma a necessidade da existência de um plano nacional, quando institui a década da educação (artigo 87), incumbindo a União de encaminhar no prazo de um ano, a partir da publicação dessa Lei, o Plano Nacional de Educação, com diretrizes e metas para os próximos dez anos, sintonizado com a Declaração Mundial sobre Educação para Todos. 
A União, apesar da sua atribuição constitucional, não priorizou a discussão do plano nacional, mantendo sua proposta engavetada, até que a sociedade civil, através do fórum Nacional em Defesa da Escola Pública, mobilizou-se com esse objetivo. O Fórum organizou o I e o II Congresso Nacional de Educação, nos anos 1996 e 1997, respectivamente, de onde saiu, a partir de um amplo debate, a proposta do Plano Nacional de Educação que ficou conhecido como PNE-Sociedade Civil.

Essa proposta foi transformada em projeto de lei, encabeçado pelo deputado Ivan Valente (PT-SP) e subscrito por mais de setenta deputados, protocolada no dia 10 de fevereiro de 1998. No dia seguinte, o Ministério da Educação protocolou a sua proposta, sendo anexada ao PNESociedade Civil. Segundo Valente, a proposta do MEC, ao contrário do PNE-Sociedade Civil, elaborado coletivamente a partir de uma ampla mobilização, "foi elaborada à moda tecnocrática, com restrita audiência social e política, de modo a garantir o essencial da política do Banco Mundial, agência que, como foi anteriormente assinalado, vem dando a tônica do elenco de medidas implementadas" (VALENTE, 2001, p. 11).

O PNE-Sociedade Civil tinha como centralidade a busca pela universalização da educação básica e procurava ampliar significativamente o acesso ao ensino superior, por meio do fortalecimento da escola pública estatal e da democratização da gestão educacional em todos os níveis, elevando o investimento público para dez por cento do produto interno bruto (PIB). A proposta do MEC, segundo Silva citando Monlevade, tinha como centralidade

a prioridade no ensino fundamental e, marginalmente, a educação infantil e a educação de jovens e adultos e ainda, em termos de ensino superior, propunha a flexibilização nas formas de oferta bem como contenção de gastos públicos em âmbito federal e estadual. Enquanto a proposta de PNE da sociedade civil previa um investimento de dez por cento do PIB de dinheiro público, a do governo federal previa um investimento de 6,5\% do PIB de dinheiro público e privado. (SILVA, 2002, p. 46)

Valente (2001), ao proceder à análise dos dois projetos de PNE, afirma que se tratavam de dois projetos antagônicos de Brasil, e não apenas duas visões e dois projetos opostos de escola e de política educacional. Havia, por um lado, um projeto democrático e popular, expresso na proposta encaminhada pelas entidades e profissionais 
vinculados à educação pública; por outro lado, a proposta do MEC, pautada nas propostas neoliberais, que traduzia a política defendida pelo capital financeiro internacional e pela classe dominante, bastante evidente nas diretrizes e nas metas do projeto que o governo apresentou.

O projeto governamental insistia na permanência da atual política educacional que se sustentava em dois pilares fundamentais: centralismo exarcebado, particularmente na esfera federal, da formulação e da gestão da política educacional e no progressivo abandono pelo Estado das tarefas de manutenção e desenvolvimento do ensino, empurrando-as, sempre que possível, para a sociedade. Trata-se de uma política que assume os parâmetros privatistas como os que devem subordinar o funcionamento da educação nacional. (VALENTE, 2001, p. 12)

O texto aprovado, tendo como base o substitutivo elaborado pelo ex-deputado Nelson Marchesan (PSDB-RS), tenta fazer uma fusão entre as duas propostas, considerando o diagnóstico da situação educacional do PNE-Sociedade Civil. Já as diretrizes, os objetivos e as metas são recuperadas do PNE-MEC. Ora, diretrizes, objetivos e metas são os elementos essenciais que constituem um plano nacional de educação. Entretanto, devem ser estabelecidas visando ao enfrentamento e à superação dos desafios apontados no diagnóstico da realidade educacional que, por sua vez, é elaborado de acordo com as concepções e a categoria de análise dos seus formuladores. O que implica estabelecer sintonia e coerência entre o diagnóstico, as diretrizes e as metas do plano, como condição para chegar aos resultados esperados.

Nesse sentido, essa fusão é por demais complicada, pois se tratava realmente de dois projetos distintos para o Brasil, de sociedade e de visões sobre qual deve ser o papel das políticas sociais, assim como a forma de sua oferta e a quem compete ofertá-la. A Constituição Federal de 1988 busca, mesmo que tardiamente e com limitações, reparar uma omissão histórica do Estado brasileiro em relação à garantia dos direitos sociais, quando estabelece políticas sociais de caráter universal. Infelizmente, a sua regulamentação, por meio das leis complementares, ocorre muito posterior à sua promulgação. No caso da educação, cerca de dez anos depois, e dentro de uma nova conjuntura política marcada pela eleição no primeiro turno de um presidente apoiado por uma coligação de centro-direita; pela eleição de um congresso nacional mais conser- 
vador; e com os movimentos sociais, sem ter o mesmo poder reivindicatório e de mobilização, com atuação diferente do processo de Assembléia Constituinte. O resultando é a elaboração de uma legislação educacional que reduz direitos, como aconteceu com o ensino obrigatório; que não regulamenta pontos importantes: como a gestão democrática e a valorização do magistério; ou que exime o Poder Público, em particular a União, de garantir, universalmente, o direito à educação.

O Banco Mundial tem papel preponderante na redefinição da política educacional, não apenas com o financiamento de alguns projetos, mas, principalmente, assessorando os governos nacionais nas suas reformas. Logicamente, que esta preponderância não implica na negação da existência de outros atores locais e internacionais que também têm peso decisivo, para não cairmos nos "clichês usuais que atribuem a um supostamente monolítico Banco Mundial a responsabilidade exclusiva pelas políticas nacionais de educação" (CORAGGIO, 1996, p. 76).

Segundo o Banco Mundial e os defensores dos ajustes neoliberais, o ponto de partida para a definição das prioridades e das alternativas para as políticas sociais diz respeito à sua viabilidade econômica, mediada pela parceria Estado e sociedade. Nesses termos, viabilidade econômica não é tratada apenas como custos crescentes dessas políticas sociais, bem como a capacidade do Estado em mantê-la, mas, sobretudo, a capacidade de introjetar os valores de mercado nas instituições públicas, entendidos como geradores de riquezas, eficiência e justiça. Outra orientação do Banco Mundial é a focalização, em que as políticas sociais deixam de ser ofertadas "para todos", perdendo seu caráter universal, sendo destinadas àqueles que estão na linha da pobreza. Propõe ainda que o Estado descentralize a execução das "ações para a comunidade, desobrigando-se de manter políticas públicas, especialmente as sociais, e repassando os encargos para outras instâncias administrativas" (LIBÂNIO et al., 2003, p. 129-130). Por último, a priorização do ensino fundamental, marginalizando as outras modalidades da educação básica e a educação de jovens e adultos, realocando recursos do ensino superior para o ensino fundamental, conseqüentemente, ampliando o acesso ao ensino superior a partir da expansão do setor privado.

Com relação à política educacional voltada para o ensino superior a partir dessa concepção, Dourado (2002) nos ajuda a revelar os indicativos dessas orientações presente no PNE do MEC, que seriam a 
diversificação do sistema por meio de políticas de expansão da educação superior, a não-ampliação dos recursos vinculados ao governo federal para esse nível de ensino, aferição da qualidade de ensino mediante sistema de avaliação, ampliação do crédito educativo envolvendo recursos estaduais, ênfase no papel da educação a distância. Destacam-se, ainda, no referido documento, a ausência de mecanismos concretos de financiamento para a efetivação das medidas, o que, certamente, resultará na concretização de novos formatos de privatização desse nível de ensino, respaldada pela interpenetração entre as esferas pública e privada. (p. 243-244)

Posto isto, a análise do PNE e dos possíveis resultados de suas metas, principalmente as garantidoras da universalização ou da ampliação do acesso à educação básica ou ao ensino superior, deve considerar não somente os dados quantitativos, mas também a concepção de política social e de país que o fundamenta. Nesse sentido, parte-se do entendimento de que ao plano nacional cabe contribuir para o planejamento - a médio e longo prazo - da educação nacional, orientando ações, dividindo responsabilidades e garantindo os recursos financeiros para o cumprimento das metas. O que significa instituir uma política educacional de Estado com ampla participação da sociedade, criando mecanismos de proteção contra as alterações motivadas apenas pelos interesses do governo de plantão e dos organismos multilaterais. Assim, os elementos constituintes da atual política educacional brasileira, tais como a concepção de políticas sociais decorrente da proposta de reforma do Estado e o papel que cabe ao PNE dentro dessa política, ajudam-nos a compreender as limitações, os alcances e os possíveis resultados do Plano Nacional de Educação.

\section{O PNE E O CONJUNTO DAS POLÍTICAS EDUCACIONAIS}

Como já afirmamos neste artigo, o PNE foi o último dos grandes marcos legais aprovado na nossa década. Entretanto, não se constituiu como o principal marco orientador da política educacional, como era de se esperar, nem tampouco é um instrumento de planejamento da educação nacional, capaz de estabelecer caminhos e orientar as ações do Poder Público. Ao contrário, o PNE limita-se a referendar e a consubstanciar a política educacional já estabelecida e praticada desde o governo FHC. 
Nota-se que o não interesse do governo federal em enviar um projeto de plano para o congresso - só o fazendo quando provocado pela sociedade civil, que protocolou o seu projeto primeiro - é bastante ilustrativo do caráter secundário dispensado ao PNE. Mesmo após a sua aprovação, o governo federal anterior (como também o faz o governo atual) continuou a operar mudanças pontuais na política educacional, ajustando-a aos interesses momentâneos e aos acordos estabelecidos com instituições de cooperação internacional, a exemplo dos diversos programas educacionais que nem sempre estavam, ou estão, em sintonia com o PNE, ou que têm como objetivo o cumprimento das diretrizes e metas do plano. Um outro exemplo são os vetos ao PNE, quase todos vinculados ao financiamento do ensino, o que praticamente inviabilizou o cumprimento das metas. As metas já tinham execução bastante comprometida, pois, ao contrário do que estabelecia o PNE-Sociedade Civil, o texto aprovado não prevê de forma detalhada os recursos necessários para o cumprimento das metas e nem suas fontes, repassando parte da responsabilidade pela execução para estados e municípios e destinando sete por cento do PIB para a educação (vetado pelo presidente Cardoso), diferente dos dez por cento defendidos pela sociedade civil.

A justificativa para os vetos partiu do Ministério da Fazenda, alegando que os artigos infringiam a Lei de Responsabilidade Fiscal e o Plano Plurianual (PPA), o que tornou o PNE um instrumento com metas importantes para a educação nacional, mas sem os meios necessários para a sua execução. Silva (2002), citando a Nota Técnica da Consultoria de Orçamento da Câmara e do Senado, desqualifica esses argumentos, indicando que não há qualquer impedimento na Lei de Responsabilidade Fiscal aos artigos vetados e que cabe ao PPA, e não ao PNE, compatibilizar os gastos disponíveis para a execução do plano, já que este tem duração mais longa que o PPA.

$\mathrm{O}$ fato de os vetos terem partido da área econômica induz-nos a compreendê-los dentro do modelo de reforma do Estado proposta pelos defensores do neoliberalismo e do ajuste estrutural imposto ao Brasil pelo Fundo Monetário Internacional (FMI), como condição para a negociação ou renegociação da dívida e para obtenção de novos empréstimos. ${ }^{1}$ No campo das políticas sociais, esse ajuste implica, basicamente, o corte ou a diminuição dos investimentos e dos gastos sociais, entre os quais a educação. O receituário recomenda também a privatização de parte dos serviços sociais públicos, entendida não apenas 
como venda da propriedade estatal, mas também como transferência da gestão, ou modelar a gestão pública de acordo com a lógica do mercado, tornando-a profissional, "despolitizada" e voltada para os resultados, o que significaria um incremento considerável "do desempenho estatal mediante a introdução de formas inovadoras de gestão e de iniciativas destinadas a quebrar as 'amarras do modelo burocrático'" (NogueIRA, 2004, p. 41), possibilitando a descentralização gerencial e a flexibilização das normas, estruturas e procedimentos.

Essa concepção parte da premissa de que estamos atravessando uma crise que envolve três aspectos: o fiscal, com a crescente demanda por benefícios sociais e de seus custos; o modelo de intervenção, com o esgotamento do modelo de Estado protetor, intervencionista e estatizante; e o modelo de organização e gestão, considerada burocrática, de alto custo e de baixa qualidade, aspectos que poriam em risco a governabilidade do país. De acordo com Cruz (2005), o conceito de governabilidade envolve três dimensões:

a primeira refere-se à capacidade do governo para identificar problemas críticos e formular as políticas apropriadas ao seu enfrentamento. A segunda diz respeito à capacidade governamental de mobilizar meios e recursos necessários à execução dessas políticas, enfatizando, além da tomada de decisão, os problemas ligados ao processo de implantação. Finalmente, em estreita conexão com o último aspecto, situa-se a capacidade de liderança do Estado, sem a qual as decisões se tornam inócuas. (p. 135)

O conceito de governabilidade, muito utilizado no Brasil pelos analistas políticos no pós-governo Collor, foi articulado ao conceito de governança por ocasião da discussão e elaboração do projeto de reforma do Estado. O termo governança foi introduzido no debate internacional pelo Banco Mundial e envolve não só o modus operandi das políticas, bem como os padrões de coordenação e de cooperação entre atores sociais e políticos (CRUz, 2005). Cruz apresenta as dimensões que constituem a governança.

A primeira liga-se à capacidade de comando e de direção do Estado, tanto internamente, em face do conjunto da máquina estatal e da sociedade, como externamente, vis-à-vis da inserção do país no sistema internacional. A segunda refere-se à capacidade de 
coordenação do Estado para atender a distintas políticas e aos diferentes interesses em jogo. Finalmente, a capacidade de implementação das políticas públicas, em parceria com o setor privado, é outro aspecto crucial, ressaltado, aliás, por várias análises como elemento essencial da crise do Estado em sua manifestação atual. (p. 137)

Assim, responsabilidade fiscal, saneamento das finanças públicas, superávit primário, pagamento dos juros da dívida, gestão gerencial, privatização, parceria público-privada passaram a ser não só a tônica dos discursos, mas o balizador das políticas sociais. A citação abaixo ajuda-nos também a compreender os motivos dos vetos presidenciais orientados pela área econômica, dos quais quatro vetos dizem respeito ao financiamento do ensino superior:

A tese repisada por 'economistas chapa-branca', representantes do Banco Mundial e do MEC, é a de que o 'Brasil não gasta pouco em educação, ele gasta mal'. Existiria uma estrutura de gastos com privilégio às classes de renda mais alta em detrimento dos mais pobres. Também se distribuiria mal os recursos entre os níveis de ensino. (VALENTE, 2001, p. 17 - grifo nosso)

Nessas circunstâncias, a meta de atingir o percentual de $30 \%$ da população na faixa etária de 18 a 24 anos no ensino superior, permanecendo essa orientação de não investimento da União nas instituições federais de ensino superior (Ifes), ficará na dependência da expansão do setor privado. Entretanto, depender exclusivamente da força do mercado para a expansão do ensino superior torna-se uma alternativa impossível de efetivação. Pacheco e Ristoff (2004) sustentam essa argumentação nos seguintes dados: primeiro, a relação candidato/vagas nas instituições privadas, índice de 1,6, torna a demanda praticamente igual a oferta, a despeito de 10,7 nas instituições públicas; segundo, o grande número de vagas ociosas no setor privado, chegando a mais de 550 mil em 2002; terceiro, $90 \%$ das instituições pertencem hoje ao setor privado, com seis das dez maiores universidades registrando crescentes índices de inadimplência e de evasão; e, por último, a renda média dos alunos no ensino médio é 2,3 vezes menor do que a das famílias dos atuais universitários. Para Pacheco e Ristoff (2004), a única possibilidade de inclusão do enorme contingente que buscará o ensino superior nos 
próximos anos, somados aos que atualmente não conseguem acesso, passa pela política de fortalecimento do setor público, o que implica romper com a lógica estabelecida para a política educacional, em particular para o ensino superior, e concluem:

Diante desse quadro, a conclusão inescapável é que o Brasil não pode mais depender exclusivamente da força inercial instalada, movida pelas demandas imediatas do mercado. Para que o país possa conquistar posição de destaque entre as nações e afirmar efetivamente a sua soberania, são necessárias ações concretas que: 1) protejam o interesse do Estado na educação superior, reafirmando a noção de que a educação é, antes de tudo, um bem público e não uma mercadoria, e 2) permitam expandir agressivamente a oferta de vagas nas instituições federais e estaduais. (p. 9)

Um outro aspecto a ser considerado é quanto à necessidade de estados e municípios também elaborarem seus respectivos planos decenais. A Constituição Federal de 1988 e a LDB/1996 não prevêem essa necessidade. Porém, a lei que aprovou o Plano Nacional de Educação, no seu artigo $2^{\circ}$, estabelece que "a partir da vigência desta Lei, os Estados, o Distrito Federal e os Municípios deverão, com base no Plano Nacional de Educação, elaborar planos decenais correspondentes" (Brasil, Lei n. 10.172/2001).

Um dos princípios básico da política educacional do governo Fernando Henrique e dos que defendem os ajustes estruturais - e do atual governo, uma vez que não dá sinais de mudanças substanciais na política educacional, tendendo, ao contrário, para o seu "aprimoramento" -, é a chamada descentralização educacional. Essa idéia é "vendida" (termo bastante apropriado para essa concepção) como sendo um mecanismo extremamente poderoso, capaz de otimizar os gastos públicos e reduzir as desigualdades sociais. Os serviços descentralizados estariam mais próximos da população e, portanto, tornando-se mais democráticos e eficazes. Haveria, nesse caso, uma redistribuição de responsabilidades entre União, estados e municípios, incentivando o envolvimento de toda a sociedade na execução da política educacional, inclusive com o aporte de recursos humanos e financeiros das famílias, de voluntários e das organizações não-governamentais (ONGs) e/ou do terceiro setor. Porém, a essa descentralização operacional das ações 
não se junta, e esse é um detalhe significativo, à descentralização do poder normativo, isto é, das prerrogativas de formular regras paramétricas das políticas públicas, incluindo, é claro, as práticas de avaliação de desempenho e distribuição dos grandes fundos públicos. (Moraes, 2002, p, 18)

No novo arranjo regulatório, a União fica com a incumbência de coordenar a política nacional de educação, exercendo também funções normativas, supletiva e redistributiva e a de avaliar a educação nacional, nos diferentes níveis e modalidades. Aos estados cabem a oferta do ensino médio e a definição de formas de colaboração com os municípios para a oferta do ensino fundamental. No tocante aos municípios, cabem a estes a responsabilidade pela oferta do ensino fundamental, prioritariamente, e pela educação infantil, sendo esta uma responsabilidade quase que exclusiva dos municípios, eximindo a União e os estados de contribuírem para o seu desenvolvimento e a sua manutenção. O município também deve mantê-la com seus próprios recursos, ou com aquilo que sobra do investimento obrigatório no ensino fundamental, o que confere um caráter não-prioritário a essa modalidade. Ou, o que é mais grave, que a educação infantil, junto com o ensino superior, seja uma modalidade com uma presença expressiva do setor privado. ${ }^{2}$ A meta que consta no PNE para a educação infantil é de ampliar a oferta de forma a atender, em cinco anos, a $30 \%$ da população de até três anos de idade e $60 \%$ da população de 4 e 6 anos e, até o final da década, $50 \%$ e $80 \%$, respectivamente, o que contraria o proposto no PNE-Sociedade Civil, que era o de universalização de toda a educação básica.

A descentralização educacional, de fato, foi defendida ao longo dos anos como uma forma de democratizar a educação nacional e de efetivar maior participação da sociedade no processo decisório. Porém, o modelo implantado no governo Cardoso significou apenas a transferência de responsabilidade pela execução da política educacional para estados, municípios e sociedade civil e o descompromisso da União para com a oferta e garantia da educação para todos. Para alguns autores efetivouse não uma descentralização, mas a desconcentração, na qual o poder local apenas executa ações concebidas no poder central, com escassos recursos para a sua execução, como demonstrou os vetos ao PNE.

A descentralização, nessa acepção, caracteriza-se pela desconcentração, isto é, cabe ao governo local apenas executar as ações 
concebidas pelo governo central, constituindo o município em ator imediato e responsável, junto com as escolas e professores, pelo enfrentamento dos complexos problemas que afetam os processos de escolarização. Em contrapartida, na abordagem democrático-participativa de descentralização, o local é concebido como meio de expansão e consolidação do espaço público, por meio de relações sociais substantivamente democráticas, incentivadas e coordenadas pelo poder local. É definidor nessa concepção a institucionalização de canais de participação da sociedade civil, invenções e renovações sociais, objetivando a incorporação das demandas sociais e o controle social da coisa pública.

É importante assinalar que a elaboração, a execução e a avaliação das políticas públicas não se pautam no referencial político-metodológico acima esboçado de descentralização. Diferentemente, o Ministério da Educação ocupa o papel de único e "legítimo" órgão formulador da política educacional, tendo como foco para a atuação suas concepções e seus interesses para o campo educacional. Decorre desse postulado o entendimento do MEC como formulador de programas federais de caráter assistencial, visando ao desenvolvimento dos sistemas de ensino a serem executados pelos estados e municípios, além de exercer também o papel de normatizador da educação nacional, desqualificando qualquer crítica ao seu papel e à política estabelecida.

Nesse sentido, parece compreensível que, mesmo sendo um imperativo legal, uma vez que parte das metas no PNE sejam executadas pelos estados e municípios, ocorra tão pouco interesse desses entes em elaborar os seus respectivos planos. Entende-se também a pouca mobilização dos profissionais e das entidades vinculados à educação por serem excluídos do processo decisório e, dessa forma, o plano aparece nas práticas cotidianas mais como peça decorativa do que como instrumento orientador da política educacional. Pesquisa recente do Ministério da Educação buscou levantar informações acerca da existência de conselhos municipais, de sistemas municipais e de planos municipais de educação, constando que somente $16 \%$ dos municípios pesquisados tinham planos municipais aprovados em lei, com maior incidência na região Sudeste (20\%) e menor na região Sul (11\%). Centro-Oeste, Nordeste e Norte contam respectivamente com 16\%, 17\% e 18\% (MEC/SICME) dos municípios com planos municipais. 
A avaliação técnica do Plano Nacional de Educação realizada pela Consultoria Legislativa da Câmara dos Deputados, em 2004, aponta para o não cumprimento de quase todas as metas do PNE. Nesse caso, como se trata de um documento de caráter meramente técnico, evidencia que uma análise mais política levará a um diagnóstico educacional muito mais grave do que o apontado e recomenda que essa análise deva ser feita com a participação da sociedade civil.

Um exemplo ilustrativo desse descaso com as metas é que, quatro anos depois de vigência do plano, segundo o censo escolar, apenas 7\% das crianças na faixa etária de 0 a 3 anos estão sendo atendidas em creches e pré-escolas, ou seja, a meta não está sendo cumprida. Significa que será necessário ampliar o atendimento dos atuais 1,3 milhão de crianças, para algo em torno de 4,3 milhões até 2011 para o cumprimento da meta. Com relação às crianças de 4 e 6 anos, o desafio se constitui em quase que duplicar o atendimento atual para que a meta seja atingida, saindo dos atuais 5,5 milhões de alunos, em 2004, para algo em torno de 8 milhões até 2011.

O ensino fundamental, aparentemente, encontra-se em situação privilegiada comparado com as outras modalidades da educação básica ou com o ensino superior. Entretanto, o documento é categórico ao enfatizar o não cumprimento da meta de universalização até 2006. Isto porque, mesmo com um atendimento em torno de $98 \%$, ainda estão fora da escola algo em torno de 800 mil crianças e adolescentes na faixa etária de 7 a 14 anos. Com um agravante: os altos índices de evasão e reprovação $(25,9 \%$ e 20,4\%), o que implica não só a garantia do acesso, mas a garantia de uma escola de qualidade e de condições para permanecer nela. Em relação ao ensino médio, para que a meta seja cumprida, o estudo indica a necessidade de inclusão de cerca de 6 milhões de jovens, o que significa maiores investimentos, conferindo a toda educação básica, e não apenas ao ensino fundamental, o caráter obrigatório e gratuito.

O governo do presidente Luiz Inácio Lula da Silva tem apresentado uma série de propostas e projetos de lei, alguns já amplamente discutidos com os setores interessados, outros nem tanto, que, de acordo com o discurso oficial, estão vinculados ao programa de governo do então candidato Lula à presidência da República. Dentre esses programas destacam-se: o sistema de cotas nas universidades, a reforma universitária, o Programa Universidade para Todos (ProUni), Universidade 
Aberta, Escola de Fábrica (ensino médio) e Brasil Alfabetizado, bem como a criação do Fundo de Manutenção e Desenvolvimento da Educação Básica e Valorização do Magistério (Fundeb), que comporiam um "pacote de bondades", segundo o próprio governo.

É interessante destacar que nas apresentações ou na exposição de motivos das propostas faz-se pouca ou nenhuma referência ao PNE, tanto no que se refere ao seu papel como instrumento de planejamento da política educacional, ou mesmo da necessidade de cumprimento de suas metas, quanto no que diz respeito à sua adequação ao contexto educacional atual, assim como sua modificação a partir das críticas formuladas pela sociedade civil. Depreende-se disso que o atual governo acaba seguindo a mesma lógica do governo anterior, destinando um caráter secundário ao PNE, em que a política de ajuste fiscal tem preponderância sobre o estabelecimento de políticas sociais que enfrentam as desigualdades sociais e econômicas do país e a educação continua sendo considerada não como um problema de recursos e, sim, de gestão.

Mesmo na versão final do Fundeb, as creches são excluídas dos cálculos do fundo, o qual não define o custo aluno qualidade, condição de garantia não só do acesso, bem como da qualidade do ensino. Também condicionou a participação da União à redução de outras despesas e não vinculou a sua participação a um percentual do fundo, mas a um montante de recursos ao final dos quatro anos. Esses indicadores demonstram a vitória da área econômica sobre o Ministério da Educação, pautada na diretriz orçamentária que pode disponibilizar 140 bilhões para o pagamento dos juros e da dívida em 2004, mas não dispõe de 4 bilhões em quatro anos para a manutenção da educação básica. A divergência apresentada publicamente entre o MEC e o Ministério da Fazenda, em relação à proposta de conversão das dívidas dos estados e municípios em investimento no ensino superior, revela projetos divergentes dentro do próprio governo, independente da concordância ou não com as propostas do MEC.

No ensino superior, as políticas de pseudogarantia da democratização do acesso, como o Financiamento Estudantil (Fies) ou o ProUni, consubstanciam apenas a transferência de recursos públicos para o setor privado, ou a legalização da sonegação de impostos dessas instituições, recursos que deveriam estar sendo aplicados na expansão da oferta no setor público. Segundo Pacheco e Ristoff (2004), 
há quem argumente que a simples transferência às universidades públicas das verbas do Financiamento Educacional (Fies) (aproximadamente 830 milhões) - hoje destinadas a alunos que estudam em instituições privadas - seria suficiente para criar aproximadamente 150 mil novas vagas nessas instituições, ou seja, seria possível mais que duplicar as 124.196 vagas na graduação oferecidas nas instituições federais. (p. 9)

Os críticos do ProUni argumentam que a renúncia fiscal provocada pelo programa significa um segundo Fies destinado ao financiamento das instituições privadas, recursos extremamente necessários às instituições públicas. Nesse sentido, o Sindicato Nacional dos Docentes no Ensino Superior (Andes-SN), aponta para a manutenção da lógica da política educacional presente no projeto de reforma universitária, quando mantém a centralidade nas mudanças gerenciais, redução do financiamento público, estabelecimento das parcerias público-privadas e a política de pseudogarantia de acesso dos pobres à universidade.

\section{CONSIDERAÇÕES FINAIS}

Ao proceder a abordagem sobre o Plano Nacional de Educação neste artigo, buscou-se não se ater à análise dos dados quantitativos para a verificação da pertinência das metas ou dos resultados do PNE, passados agora quatro anos de sua aprovação. Construiu-se uma trajetória para a argumentação que partiu da contextualização histórica do plano e de seu papel dentro da política educacional consolidada durante o governo Cardoso, relacionando-o com as propostas de reforma do Estado e de ressignificação do seu papel, das políticas sociais e da sociedade.

Entende-se que esse caminho justifica-se para não tomarmos o PNE como um instrumento da política educacional desvinculado dos demais marcos e mecanismos legais e da concepção de política social e educacional estabelecida no último governo federal, ou de tomá-lo por partes, identificando o que é "bom" ou o que é "ruim" (o que deve ser mantido e o que deve ser mudado) para a construção de uma educação pública de qualidade, democrática e universal. Permanecer nessa perspectiva induz a restringir a nossa luta também na defesa de mudanças pontuais no plano, como a derrubada dos vetos, que pode contribuir para minimizar algumas mazelas da educação nacional, em particular no ensino superior, mas não muda a concepção e a essência da política educacional. 
Também não se acredita que mudança pontual em tópicos da política educacional, como o faz o governo do presidente Luiz Inácio Lula da Silva - a exemplo da proposta de reforma universitária -, mesmo que essas propostas sejam desejáveis, como a criação do Fundo de Manutenção da Educação Básica (Fundeb), em substituição ao Fundef; e, desta vez, com a garantia de aporte financeiro da União, ou iniciativas louváveis, como a da senadora Heloísa Helena (PSOL-AL), que apresentou projeto tornando obrigatório a educação infantil (Proposta de Emenda à Constituição n. 40/2000), possam produzir os efeitos esperados para mudar o quadro educacional brasileiro se não for alterada a lógica estabelecida para as políticas sociais, em particular as da educação, o que só será possível a partir da instituição de um Estado verdadeiramente democrático, participativo e redistributivo e com a ampla participação da sociedade civil na definição, gestão e acompanhamento das políticas públicas.

\section{ABSTRACT}

The aim of this article is to understand the Brazilian National Education Plan (PNE), starting from an analysis of the process of its approval in law by Congress, within the context of changes in educational policy in recent years, in the hope of adapting it to proposed reforms and changes in the Brazilian State, in accordance with the orientation of organizations for international cooperation. The objective is to show the importance of the PNE in the present educational debate.

Key words: National Education Plan (PNE); educational policy; the State; structural adjustments.

\section{NOTAS}

1. Para maior aprofundamento acerca do modelo de reforma do Estado brasileiro cf. Pereira.

2. De acordo com o censo escolar realizado pelo Instituto Nacional de Estudos e Pesquisas Educacionais Anísio Teixeira (Inep/MEC), em 2002, a participação do setor privado nas matrículas nas creches correspondia a $29,9 \%$ do total; em 2003, subiu para 37,9\%, permanecendo nesse patamar em 2004. Com relação à participação nas matriculas da pré-escola, em 2002 e 2003, ficou em 25,5\% do total, ampliando para 26,6\% em 2004. 


\section{REFERÊNCIAS}

ASSOCIAÇÃONACIONAL DOS DOCENTES DO ENSINO SUPERIOR (Andes$\mathrm{SN})$. Agenda para a educação superior: uma proposta da Andes-SN para o Brasil de hoje. Brasília, 2005. Disponível em: <htpp;//www.andes.org.br>. Acesso em: 15 jun. 2005.

AZEVEDO, J. M. L. Implicações da nova lógica de ação do Estado para a educação municipal. Educação \& Sociedade, v. 23, n. 80, p. 49-71, 2002.

BRASIL. Lei n. 9.394, de 20 de dezembro de 1998. Dispõe sobre a lei de diretrizes e bases da educação nacional. Brasília. . Constituição Federal. Brasília, 1988.

CÂMARA DOS DEPUTADOS. Avaliação técnica do plano nacional de educação. Brasília: Coordenação de Publicações, 2004.

CRUZ, J. A. da. Organizações não-governamentais, reforma do Estado e política no Brasil: um estudo com base na realidade de Goiás. Campinas, 2005. Tese (Doutorado em Educação) - Faculdade de Educação, Universidade Estadual de Campinas.

CORAGGIO, J. L. Propostas do Banco Mundial para a educação: sentido oculto ou problemas de concepção? In: HADDAD, S; TOMMASI, L. de; WARD, M. J. O Banco Mundial e as políticas educacionais. São Paulo: Cortez, 1996.

DOURADO, L. F. Reforma do Estado e as políticas para a educação superior no Brasil nos anos 90. Educação \& Sociedade, v. 23, n. 80, p. 49-71, 2002.

INSTITUTO NACIONAL de ESTUDOS e PESQUISAS EDUCACIONAIS (Inep/ MEC). Censo Escolar. Brasília, 2005. Disponível em: <Htpp;//www.inep.org.br>. Acesso em: 10 jun. 2005.

LIBÂNIO, J. C; OLIVEIRA, J. F.; TOSCHI, M. S. Educação escolar: políticas, estrutura e organização. São Paulo: Cortez, 2003.

MORAES, R. C. Reformas neoliberais e políticas públicas: hegemonia ideológica e redefinição das relações Estado-sociedade. Educação \& Sociedade, v. 23, n. 80, p. 13-24, 2002.

NOGUEIRA, M. A. Um Estado para a sociedade civil: temas éticos e políticos da gestão democrática. São Paulo: Cortez, 2004.

PACHECO, E; RISTOFF. D. Educação superior: democratizando o acesso. Brasília: Inep, 2004.

VALENTE, I. Plano nacional de educação. Rio de Janeiro: D\&P, 2001.

SILVA, C. C. O plano nacional de educação. Revista Educação Municipal, n. 5, p. 45-54, 2002.

SAVIANI, D. A nova lei da educação: trajetória, limites e perspectivas. Campinas: Autores Associados, 1997. 